\title{
Ten years of neonatal autopsies in tertiary referral centre: retrospective study
}

\author{
Malcolm Brodlie, Ian A Laing, Jean W Keeling, Kathryn J McKenzie
}

\begin{abstract}
Objectives To measure the neonatal autopsy rate at a tertiary referral centre and identify trends over the past decade. To identify factors that may influence the likelihood of consent being given for autopsy. To examine any discordance between diagnoses before death and at autopsy.

Design Retrospective review of patients' records. Setting Tertiary neonatal referral centre affiliated to university.

Outcome measures Sex, gestational age, birth weight, type of delivery, and length of stay in neonatal unit for baby. Maternal age, marital status, history of previous pregnancies, and details of who requested permission for autopsy. Concordance between diagnoses before death and at autopsy.

Results An autopsy was performed in 209/314 (67\%) cases. New information was obtained in $50(26 \%)$ autopsies. In six (3\%) cases this information was crucial for future counselling. In 145 (74\%) there was complete concordance between the clinical cause of death and the findings at autopsy. From 1994 onwards the autopsy rate in the neonatal unit fell. The only significant factor associated with consent for autopsy was increased gestational age.

Conclusions Important extra information can be gained at neonatal autopsies. This should help parents to make an informed decision when they are asked to give permission for their baby to have an autopsy. These findings are of particular relevance in view of the recent negative publicity surrounding neonatal autopsies and the general decline in the neonatal autopsy rate over the decade studied.
\end{abstract}

\section{Introduction}

Autopsy has been important in medicine since the 15 th century ${ }^{1}$ and has contributed greatly to clinical knowledge..$^{2-4}$ Neonatal autopsy has a particularly valuable role in the counselling of families after the loss of an infant as it can help the grieving process, improve parental understanding, and alleviate concerns over prenatal events. ${ }^{5-9}$ Genetic conditions or obstetric factors of relevance to future pregnancies may also be identified. ${ }^{10}$

Recently the rate and perceived importance of autopsies of adults has declined considerably. ${ }^{11-14}$ Conversely rates of neonatal autopsy have generally remained higher, with previous reports ranging from $59 \%$ to $81 \% .^{3}{ }^{13-17}$ In 2000, however, the neonatal autopsy rate declined in Illinois. ${ }^{18}$ Parental consent is thought to be the major limiting factor. ${ }^{16}$ The public's exposure to the purposes and value of the autopsy is sparse, and perceptions are often dominated by melodramatic treatment in the media. ${ }^{19}$

We measured the rate of neonatal autopsy at a tertiary referral centre over the past decade to investigate the role of various factors in determining consent for autopsy. We also examined the yield of new information in terms of discordance between diagnoses before and after death.

\section{Methods}

We carried out the study in a neonatal unit in the main tertiary neonatal referral centre for the south east of Scotland. We included records of all deaths in the neonatal unit from 1 January 1990 to 31 December 1999. The policy in the unit is that a senior clinician, normally the relevant consultant, approaches relatives for consent for autopsy after each death. Autopsies were performed only after parental consent or at the request of the procurator fiscal. Each examination was performed by one of four consultant paediatric pathologists using standard techniques. ${ }^{20}$

We recorded the cause of death from the original death certificate, which was normally completed by a consultant. We obtained maternal and infant details from the original medical records and abstracted autopsy findings from the concluding summary of the pathologist's report. Death certificates were not available for 1990-2; in these cases the cause of death was determined by a consultant neonatologist after review of the patients' records.

We used a modified version of previously published schemes ${ }^{11} 18$ to classify the concordance between autopsy findings and diagnoses before death (table 1). We compared the proportion of events in each group using the $\chi^{2}$ test for discrete variables and Student's $t$ test for numerical variables.

\section{Results}

In over a quarter of cases new information was obtained at autopsy (see table A on bmj.com for further details). A single class Ia diagnosis of sigmoid volvulus was identified along with five class $\mathrm{Ib}$ diagnoses with implications for genetic advicenamely, Smith-Lemli-Opitz type II syndrome, De Lange's syndrome, ornithine carbamyltransferase defi-

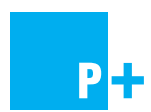

Three tables with further data can be found on bmj.com 
Table 2 Factors related to baby and mother according to whether autopsy was performed

\begin{tabular}{|c|c|c|c|c|c|c|}
\hline \multirow[b]{2}{*}{ Category } & \multicolumn{2}{|c|}{ Autopsy performed } & \multicolumn{2}{|c|}{ No autopsy } & \multirow[b]{2}{*}{ P value* } & \multirow{2}{*}{$\begin{array}{l}\text { Data not } \\
\text { available }\end{array}$} \\
\hline & Mean (range) & SD & Mean (range) & SD & & \\
\hline Gestational age (weeks) & $32.2(22-42)$ & 6.44 & $30.1(23-42)$ & 6.79 & 0.0066 & 15 \\
\hline Birth weight $(\mathrm{g})$ & $1828(400-5250)$ & 1179 & $1669(365-5230)$ & 1246 & 0.1402 & 7 \\
\hline Length of stay (days) & $15.4(1-210)$ & 35.6 & $14.2(1-240)$ & 32.3 & 0.3807 & 6 \\
\hline Age at death (days) & $15.8(1-210)$ & 35.6 & $15.2(1-210)$ & 34.8 & 0.4465 & 28 \\
\hline Maternal age (years) & $27.3(15-43)$ & 5.81 & $28.0(16-42)$ & 6.16 & 0.1923 & 51 \\
\hline
\end{tabular}

${ }^{*}$ Mean of each group compared with Student's $t$ test.

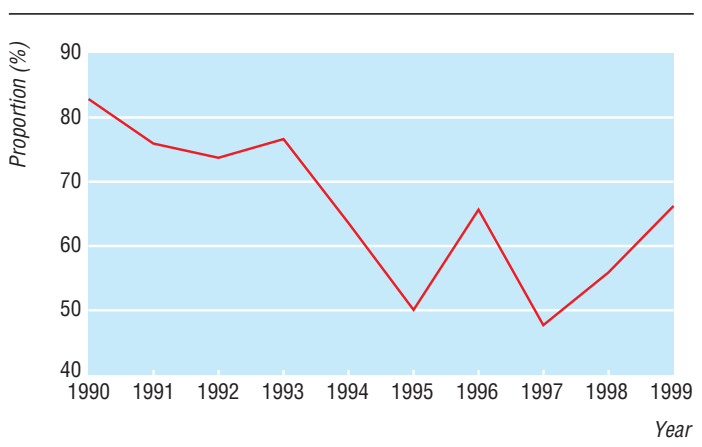

Autopsy rate in neonatal unit (1990-9)

ciency, DiGeorge syndrome, and $\mathrm{GM}_{1}$ gangliosidosis. An autopsy was performed in 209 of the 314 cases studied (see table B on bmj.com). The overall rate of neonatal autopsy of $67 \%$ remained substantially higher than the prevailing rate in adults. From 1994 onwards, however, the annual autopsy rates dropped below levels earlier in the decade (figure). Gestational age was the only factor that was found to differ significantly between the groups who did and did not give permission for autopsy, with means of 32 and 30 weeks respectively (table 2). Details of other factors that we examined and that were not associated with consent for autopsy can be found in table $\mathrm{C}$ on bmj.com.

\section{Discussion}

Earlier studies have reported higher yields of new information from neonatal autopsies, ranging from $34 \%$ to $48 \%$, though classification criteria and

\section{What is already known on this topic}

The neonatal autopsy rate dropped in Illinois during the 10 years from 1984 to 1993

Over recent years there has been a large amount of negative publicity surrounding neonatal autopsies in the United Kingdom

\section{What this study adds}

Over a quarter of neonatal autopsies yielded new information; in 3\% of cases this information was crucial

This finding is likely to be of use to bereaved parents who are asked to give permission for autopsy and provides a more positive perspective on the utility of neonatal autopsies procedures varied between publications. $.^{10} 13-151821$ In our study a single observer classified the level of concordance between diagnoses before death and at autopsy. Review by a multidisciplinary team, including a pathologist, may have resulted in a higher yield. We abstracted clinical diagnoses from the death certificates when they were available. The reliability of death certificates largely depends on how accurately clinicians record clinical information. ${ }^{22}$ In Edinburgh certificates were normally completed after consideration of the case by the consultant in charge.

Demographic features such as the sex of the infant and maternal age or marital status have never been identified as significant determinants of consent for neonatal autopsy. ${ }^{3}{ }^{16}$ VanMarter et $\mathrm{al}^{17}$ and Maniscalco and Clarke ${ }^{3}$ also found gestational age to be a significant factor. Possibly clinicians are less likely to encourage parents to give consent for autopsy in extremely preterm infants. ${ }^{17}$ In general the strength of requests for individual autopsies is likely to vary because clinicians will have different views as to its importance in a specific case.

The finding that in about a quarter of cases new information was gained is likely to be of use to bereaved families when they are considering permission for an autopsy. The proportion of neonatal deaths attributed to major genetic or congenital abnormalities has increased. Accurate diagnosis in such cases, either before or after death, is highly important for future counselling. Information obtained at autopsy may not have directly affected clinical management but is essential for audit or educational purposes. ${ }^{21}$ Arguably the greatest value of the neonatal autopsy is to families during the grieving process. Such unique benefits are far more difficult to quantify. ${ }^{93}$

The apparent reduction in the neonatal autopsy rate in Edinburgh over the decade studied warrants serious debate. There is no obvious single explanation but possible influences include a shift in the attitude of clinicians towards autopsies or a change in the public's willingness to grant permission. Economic or procedural considerations did not feature during the period studied. The recent high profile disclosure concerning organ retention in the United Kingdom ${ }^{24}$ can only have served to harm the public's view of autopsies. A concerted effort will be needed to promote the value and purposes of the neonatal autopsy.

We thank Gill Mitchell for her invaluable help in tracing patient records. We are grateful to Professor Neil McIntosh for his comments on the original protocol.

Contributors: MB contributed to the planning of the study, collated and analysed the data, and wrote the paper. This project began as a special study module part of the University of Edinburgh phase III MBChB course. IAL supervised the planning and execution of the study, contributed to the writing of the 
paper, and will act as guarantor. JWK and KJMcK provided advice during the study and commented on the paper.

Funding: None.

Competing interests: None declared.

1 Dorsey DB. A perspective on the autopsy. Am J Clin Pathol 1977;69:217-9.

2 Landefeld CS, Chren MM, Myers A, Geller R, Robbins S, Goldman L. Diagnostic yield of the autopsy in a university hospital and a community hospital. N Engl J Med 1988;318:1249-54.

3 Maniscalco WM, Clarke TA. Factors influencing neonatal autopsy rate. Am J Dis Child 1982;136:781-4.

4 Berthrong M. The autopsy as a vehicle for the lifetime education of pathologists. Arch Pathol Lab Med 1984;108:506-9.

5 Hirsch CS. Talking to the family after an autopsy. Arch Pathol Lab Med 1984;108:513-4.

6 Reynolds RC. Autopsies-benefits to the family. Am J Clin Pathol 1977;69:220-2

7 Rowe J, Clyman R, Green C, Mikkelsen C, Haight J, Ataide L. Follow-up of families who experience a perinatal death. Pediatrics 1978;62:166-70.

8 Valdes-Dapena M. The postautopsy conference with families. Arch Pathol Lab Med 1984;108:497-8.

9 Beckwith JB. The value of the pediatric postmortem examination. Pediat Clin North Am 1989;36:29-35.

10 Saller DN Jr, Lesser KB, Harrel U, Rogers BB, Oyer CE. The clinical utility of the perinatal autopsy. JAMA 1995;273:663-5.

11 Goldman L, Sayson R, Robbins S, Cohn LH, Bettmann M, Weisberg M. The value of the autopsy in three medical eras. $N$ Engl $J$ Med 1983;308:1000-5.
12 Burrows S. The postmortem examination. Scientific necessity or folly? JAMA 1975;233:441-3.

13 Dhar V, Perlman M, Vilela MI, Haque KN, Kirpalani H, Cutz E. Autopsy in a neonatal intensive care unit: utilization patterns and associations of clinicopathologic discordances. J Pediatr 1998;132:75-9.

14 Meier PR, Manchester DK, Shikes RH, Clewell WH, Stewart M. Perinatal autopsy: its clinical value. Obstet Gynecol 1986;67:349-51.

15 Craft H, Brazy JE. Autopsy-high yield in neonatal population. Am J Dis Child 1986;140:1260-2.

16 Khong TY, Mansor FAW, Staples AJ. Are perinatal autopsy rates satisfac tory? Med J Austr 1995;162:469-70.

17 VanMarter LJ, Taylor F, Epstein MF. Parental and physician-related determinants of consent for neonatal autopsy. Am J Dis Child 1987;141:149-53.

18 Kumar P, Angst DB, Taxy J, Mangurten HH. Neonatal autopsies: a 10-year experience. Arch Pediatr Adolesc Med 2000;154:38-42.

19 Brown HG. Lay perceptions of autopsy. Arch Pathol Lab Med 1984;108:446-8

20 Keeling JW. The perinatal necropsy. In: Keeling JW, ed. Fetal and neonatal pathology. London: Springer, 1987.

21 Porter HJ, Keeling JW. Value of perinatal necropsy examination. J Clin Pathol 1987;40:180-4.

22 Kircher LT. Autopsy and mortality statistics: making a difference. JAMA 1992;267:1264-8

23 Berger LR. Requesting the autopsy: A pediatric perspective: psychosocial and professional aspects of the autopsy in caring for the dying child and his family. Clin Pediatr (Phila) 1978;17:445-52.

24 Hunter M. Alder Hey report condemns doctors, management, and coroner. $B M J$ 2001;322:255.

(Accepted 5 November 2001)

\section{Synergism between allergens and viruses and risk of hospital admission with asthma: case-control study}

Rosalind M Green, Adnan Custovic, Gwen Sanderson, Jenny Hunter, Sebastian L Johnston, Ashley Woodcock more allergens, and viral detection considerably increased the risk of being admitted with asthma (8.4, 2.1 to $32.8 ; \mathrm{P}=0.002)$.

Conclusions Allergens and viruses may act together to exacerbate asthma.

\section{Introduction}

Asthma costs 1-2\% of the total health budgets in direct costs, with equally large indirect costs for time lost from work and reduced productivity. ${ }^{12}$ Much of these costs come from hospital admissions. Being admitted to hospital with asthma is also an important risk factor for death from the condition. ${ }^{3}$

Of 450000 adults admitted yearly with asthma to emergency departments in the United States, an estimated 200000 were sensitised to mite, cat, or cockroach allergen. ${ }^{4}$ Viral respiratory infections have been associated with most acute exacerbations of wheeze in childhood. ${ }^{5}$ In the early part of each school term there is an increase in hospital admissions for asthma associated with the acquisition of new viruses. ${ }^{6}$ An interaction has been suggested between sensitisation and virus infection in exacerbating asthma in children. Few studies have been conducted in adults, although there is evidence that viral infections are associated with many exacerbations of asthma. ${ }^{8}$ In experimental studies synergistic effects have been shown between allergens and viruses. ${ }^{910}$ No studies have investigated an interaction between sensitisation, exposure to allergens, and viral infections in real life exacerbations of asthma. We therefore determined their relative importance in the group admitted to hospital (odds ratio 2.3, 95\% confidence interval 1.0 to $5.4 ; \mathrm{P}=0.05$ ), whereas the combination of sensitisation, high exposure to one or

\section{ELPS}

The full version of this article appears on bmj.com

North West Lung

Centre,

Wythenshawe

Hospital,

Manchester

M23 9LT

Rosalind M Green research registrar

Adnan Custovic

National Asthma

Campaign senior

clinical research fellow

Ashley Woodcock

professor

Department of

Respiratory

Medicine, National

Heart and Lung

Institute, Faculty of

Medicine, Imperial

College of Science,

Technology and

Medicine, London

W2 1 PG

Gwen Sanderson

research technician

Sebastian L

Johnston

professor

University

Medicine,

Southampton

General Hospital,

Southampton

SO9 6YD

Jenny Hunter research technician

Correspondence to: A Custovic

acustovic@fs1.

with.man.ac.uk

BMJ 2002;324:763-6 